\title{
Application of Phage-Displayed Peptides in Tumor Imaging Diagnosis and Targeting Therapy
}

\author{
Chunyan $\mathrm{Li}^{1} \cdot \mathrm{Jia} \mathrm{Li}^{1} \cdot \mathrm{Ying} \mathrm{X}{ }^{1} \cdot \mathrm{Ying}_{\mathrm{Zhan}}{ }^{2} \cdot \mathrm{Yu} \mathrm{Li}^{1} \cdot$ Tingting Song $^{1} \cdot$ Jiao Zheng ${ }^{1} \cdot$ Hong Yang $^{1}$
}

Received: 10 May 2020 / Revised: 7 August 2020 / Accepted: 14 August 2020 / Published online: 3 September 2020

(c) Springer Nature B.V. 2020

\begin{abstract}
Phage display is an effective and powerful technique that provides a route to discovery unique peptides targeting to tumor cells. Specifically binding peptides are considered as the valuable target directing molecule fragments with potential efficiency to improve the current tumor clinic, and offer new approaches for tumor prevention, diagnosis and treatment. We focus on the recent advances in the isolation of tumor-targeting peptides by biopanning methods, with particular emphasis on molecular imaging, and pharmaceutical targeting therapy.
\end{abstract}

Keywords Targeting peptides · Phage display · Tumor imaging diagnosis · Tumor targeting therapy

\section{Introduction}

Cancer is the leading cause of death worldwide (Bray et al. 2018), associated mainly with the lack of precise detection for early diagnosis, and non-availability of tumor specific drug delivery system. Current regular medical cares for cancers include the diagnosis by endoscopy, biopsy, X-ray, and treatment by surgical operation, radiotherapy, and chemotherapy. Moreover, non-targeted diagnosis methods are not sensitive enough to screen the patients with early tumor development, and dose-dependent toxicities and drug-resistance of chemotherapy limit clinical applications. Therefore, the developments of targeted diagnosis and chemotherapy for cancer clinic are the most important approaches to improve the current efficiency of cancer diagnosis and treatment to save lives of patients.

Both molecular imaging and targeted drug delivery need tumor-specific molecular fragments as effective targeting vehicles to deliver imaging probes and chemotherapeutics to tumor sites. People have tried many strategies to construct the approaches and been awaked by many difficulties needed to be considered also, such as the specificity/sensitivity of

Hong Yang

yanghongfck@163.com

1 Department of Obstetrics and Gynecology, The First Affiliated Hospital of Air Force Medical University, 127 West ChangLe Road, Xi' an 710032, Shaanxi, China

2518 Hospital of PLA, Xi' an 710043, Shaanxi, China the structures, extracellular degradation, endocytosis and others. Antibody was the first choice to be used as the targeting element, but its application was limited because of slow binding kinetics, immunogenicity, production costs and nonspecific uptake by liver and reticuloendothelial system (Deutscher 2010). Peptide, a fragment with small sizes, possessing biological activity, is pursued as attractive targeting moieties due to its low immunogenicity, high affinity, rapid tissue penetration, low manufacturing cost and fast clearance from blood circulation, flexible in chemical conjugation and compatible with fluorescence dyes ( $\mathrm{Li}$ and Cho 2010; Newman and Benoit 2018). Successful examples include transferrin and octreotide that have been used as targeting delivery peptides in colon cancer and some neuroendocrine tumors therapy. Targeting peptides are generally discovered via biopanning of phage display libraries.

Biopanning is well known as a high-throughput peptide screening method that was developed in 1985 (Kugler et al. 2013; Smith 1985) and awarded Nobel Prize for Chemistry in 2018, and has been successfully applied in different biomedical areas including vaccine development, cancer research, drug discovery, epitope mapping, and proteinprotein interactions. For phage display libraries, the most commonly used phage vector is the M13 phage, the foreign small peptides can be fused to minor coat protein III (406 residues, 3-5 copies of the peptide) or major coat protein VIII (50 residues, 2700 copies of the peptide). Fused proteins are presented on the surface of phage produced in Escherichia coli (E. coli). Here, the genotype and phenotype 
of exogenous peptides are linked by fusing the corresponding gene fragments to the coat proteins without compromising phage infectivity or propagation ability. The technology provides rapid identification of peptide ligands for various target molecules or structures, such as antigens (Lim et al. 2019), antibodies (Hintz et al. 2019), cell surface receptors (Ferreira et al. 2019; Li et al. 2017), biological, inorganic and organic materials (Martins et al. 2016) and even tissues in vivo (Wada et al. 2019). The biopanning procedure is more likely to keep native structure and functional conformation of proteins than purified protein, and requires no previous knowledge of molecular composition at the site of interest. Meanwhile, the peptides obtained by biopanning possess high affinity and specificity on target sites.

In the paper, we will highlight some successful applications of peptides with particular emphasis on molecular imaging, and pharmaceutical targeting therapy.

\section{Biopanning}

The affinity selection using phage display is called biopanning. The biopanning usually consists of four main successive steps: (1) phage-displayed peptides mimicked binding, (2) washing away the non-specifically bound phages, (3) eluting off the specifically bound phages, (4) amplifying the eluted phages, tittering the sub-library and starting a new biopanning round. The process of selection and amplification is normally repeated 3-4 rounds to ensure the enrichment of specifically bound phages (Fig. 1).In vitro biopanning is usually chosen for a variety of targets on cell surface or molecules, which includes biopanning on the immobilized molecules (Rahbarnia et al. 2017; Zhao et al. 2018), solution biopanning (Fouladi et al. 2019;
Thanongsaksrikul et al. 2018), selection on whole cells (Carneiro et al. 2014; Li et al. 2017; Yeh et al. 2016), reverse biopanning (Ferraro et al. 2013), display of established internalizing peptides (Rangel et al. 2012). Molecules screening by this approach are more likely to keep native conformation, and recognize specific post-translational modifications (Kehoe et al. 2006; Velappan et al. 2019). In addition, neither purification nor prior knowledge of a particular target receptor is required in advance. Although a large variety of receptors can be screened at one time, it is worth noting that the identification is laborintensive, nonefficient and low throughput, and only a few can be preliminarily identified by co-immunoprecipitation, affinity chromatography, yeast-two-hybrid system, protein mass spectrometry analysis and other complex methods.

In addition to in vitro selection, in vivo biopanning is also a powerful method for identification of targeting ligands homing to a specific tissue or organ. In vivo biopanning can maximumly simulate the living circumstance and improve the binding activity of peptides to specific targets. Briefly, the phage peptide library is administered intravenously to animals and allowed to circulate for few minutes. Subsequently, the animal is sacrificed and phages are recovered from the interested organs or tissues, amplified in E. coli and then used in the next biopanning round. A variety of tissue-specific peptides have been identified that bind brain (Acharya et al. 2020), breast (Lu et al. 2013), esophagus (Sturm et al. 2013), etc. However, in vivo biopanning is usually limited by a relatively short circulation half-life, and it has predominately selected peptides binding to tumor vasculature components and not directly to tumor cells. In fact, some peptides are found to recognize not only the surface of tumor cells but also tumor vessels that they may share the similar receptors. Consequently, these peptides may serve
Fig. 1 Biopanning steps (modified from Kügler et al). (1) mimicked binding phages to targets, (2) washing away unbound phages, (3) eluting off specific bound phages, (4) enriching the specifically bound phages for next round of biopanning

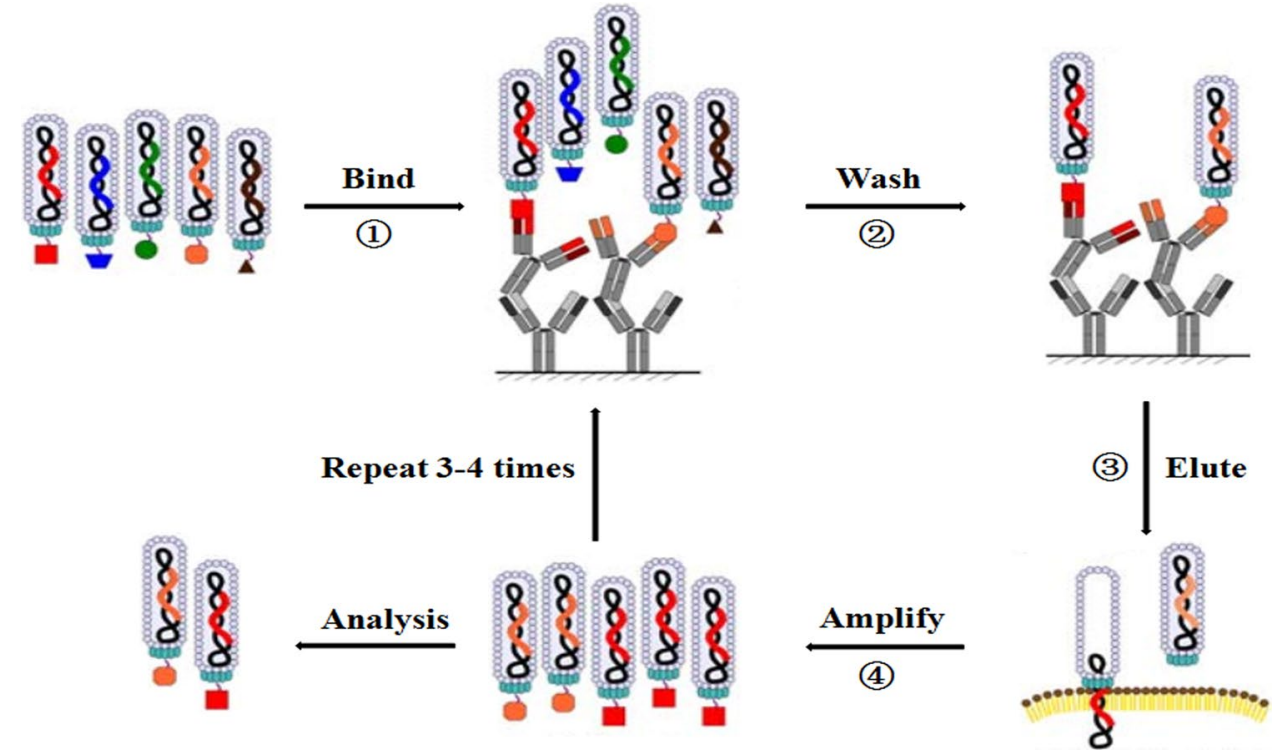


additional advantages as excellent candidates for drug delivery and cancer treatment.

\section{Potential Applications of Targeting Peptides}

\section{Peptides for Tumor Biomarkers}

Tumor biomarkers are the molecular indicators found in blood, other body fluids, or on tissues that can be interrogated to evaluate disease status and pharmacologic responses to therapeutic interventions. Biomarkers include RNAs (Capula et al. 2019; Funamizu et al. 2019), hormones (Costante and Meringolo 2020; Riccetti et al. 2017), as well as different functional subgroups of proteins such as enzymes (Miao et al. 2013), glycoproteins (Luo et al. 2018), oncofetal antigens (Feng et al. 2017) and receptors. Selected targeting peptides are currently used as biomarkers for some cancers with high incidence (Luna Coronell et al. 2012).

Prostate-specific antigen (PSA) is a crucial biomarker for the diagnosis and monitoring therapy of prostate cancer due to its highly restricted tissue distribution (Armbruster 1993). Investigators isolated and characterized specific PSA peptide mimotopes produced an antibody immune response that recognized the PSA protein, results indicated that the peptide can be developed into a prostate cancer specific biomolecular probe in bioanalysis (Lang et al. 2014). Integrin $\alpha 11$ / $\beta 1$, a marker of aggressive tumors that indirectly stimulate cancer-stromal stiffness and tumor progression, may be an attractive target for anti-cancer therapeutic antibodies. Gallo successfully selected functional antibodies that competed with collagen-I for binding to Integrin $\alpha 11 / \beta 1$ to inhibit cell adhesion by in situ antibody phage display (Gallo et al. 2020). CD44, a cancer-associated membrane glycoprotein involved in cell adhesion, tumor progression and drug-resistance, is a potential diagnostic target for cancer detection. A peptide CV-1 (THENWPA) specifically bound to gastric cancer cell surface marker CD44 was selected, identified and demonstrated as a promising probe for early molecular imaging and monitoring CD44v-positive stomach tumors (Zhang et al. 2016).

Pancreatic ductal adenocarcinoma (PDAC) carries an extremely poor prognosis, typically exhibiting severe resistance to existing therapies. Kelly successfully identified membrane-localized plectin- 1 as a potential biomarker of PDAC by biopanning and proteomics analysis, which may have clinical utility in the diagnosis and management of PDAC in humans as a targeted imaging agent (Kelly et al. 2008a). They also isolated a novel peptide with both high specificity and sensitivity for hepsin, an emerging and potential new prostate cancer biomarker to significantly improve pharmacokinetics and cancer detection (Kelly et al. 2008b).

\section{Peptides for Molecular Imaging Diagnosis}

Conventional methods for imaging diagnosis include computed tomography (CT), magnetic resonance imaging (MRI), near-infrared imaging (NIRF), positron emission tomography (PET) and single photon emission computed tomography (SPECT) while suited for big sizes or whole body imaging. These methods are limited to monitor more microscopic processes in real time. Hence, more sensitive imaging technologies are needed to diagnose cancers early and specifically. Molecular imaging usually utilizes specific molecular probes targeting unique receptors (molecules) of tumor tissues or other diseased tissues to form the localized pictures of image contrast to facilitate detection or response to therapy as well as to investigate drug efficacy (Deutscher 2010; Li and Cho 2012).

The targeting peptide probe is the key element for the development of molecular imaging. Peptides may offer fundamental advantages over antibodies because of low molecular weight, favorable biodistribution profiles, high uptake in the target and rapid clearance from the bloodstream. Furthermore, peptides can be labeled with the appropriate moieties or conjugated with nanoparticles on demand with the help of sophisticated bio-conjugating or radio-labeling techniques (Lee et al. 2010).

\section{Radiolabeled Peptides}

The radionuclide-based PET and SPECT imaging are sensitive molecular imaging techniques, and provide enough sensitivity and visualization of interactions between physiological targets and ligands such as disease-related peptidebinding receptors. To develop radiolabeled peptide probes, a targeting peptide should be radiolabeled efficiently with high specific radioactivity and be stable under physiological conditions. The common radionuclides such as ${ }^{99 \mathrm{~m}} \mathrm{Tc},{ }^{123} \mathrm{I}$, ${ }^{111} \mathrm{In},{ }^{18} \mathrm{~F},{ }^{64} \mathrm{Cu},{ }^{68} \mathrm{Ga}$ for diagnostic use, or ${ }^{90} \mathrm{Y}$ and ${ }^{177} \mathrm{Lu}$ for therapeutic use have been employed. A number of peptides have been screened, synthesized and radiolabeled to be currently under preclinical or clinical investigation to determine their clinical potential in cancer diagnosis.

Recently, a cysteine-constrained randomized 7-mer library was selected using HER 3 as target, and a peptide HER3P1 which bound with high selectivity to HER3 was isolated and labeled with ${ }^{68} \mathrm{Ga}$ for PET imaging of HER3-positive tumors, results indicated that HER3P1 has potential utility as a clinical imaging agent (Larimer et al. 2018). Larimer et al. also reported an ${ }^{111}$ In-DOTA labeled ERBB2-targeted SPECT imaging peptide 1-D03 (MEGPSKCCYSLALSH) may serve as a viable candidate for clinical imaging studies of breast carcinoma because of rapid clearance and tumor specificity (Larimer et al. 2014). Furthermore, gastrin-releasing peptide (Ghosh et al. 2019), 
cholecystokinin-2 (Kossatz et al. 2013), melanocortin-1 (Li et al. 2019a), epidermal growth factor (Ulaner et al. 2018), neurotensin (Yin et al. 2017), somatostatin (Liu et al. 2018) and glucagon-like peptide-1 (Stahle et al. 2018) receptors have been successfully applied for early cancer imaging diagnosis.

\section{Bioluminescent and Fluorescent Labeled Peptides}

Microscopic optical imaging techniques have already been developed for a variety of uses in molecular and cellular biological studies, allowing the rapid visualization, characterization and quantification of biological processes at the cellular and subcellular level within intact living organisms. Compared with other imaging modalities, optical imaging is highly sensitive, non-invasive, real-time and safe detection using available instruments at an acceptable cost (Lee et al. 2010; Licha and Olbrich 2005).

Bioluminescent imaging is a standard optical molecular imaging technique that cells producing bioluminescent proteins such as luciferase and generating intensively light signal at a target region following by the reaction between specific enzyme and appropriate substrate (Deutscher 2010; Khemthongcharoen et al. 2014). Bioluminescent imaging allows quick and easy localization and visualization of biological processes in multiple diseases. Simultaneously, the development of far-red and near-infrared systems enhanced sensitivity and resolution in deep tissue and wide applications (Mezzanotte et al. 2017), such as cancer researches, protein-protein interactions, ligand-receptor interactions, and pharmacokinetic study in animal models. Konkalmatt and colleagues inserted plectin-1 targeting peptide (PTP) specifically bound to pancreatic ductal adenocarcinoma into the loop IV region of the AAV, and then injected intravenously with luciferase receptor vectors packaged in the AAV-PTP capsid to mice, and light output was detected almost exclusively in the tumors with little or no signal from the healthy pancreas, which may open a promising new avenues for the early diagnosis, and treatment of pancreatic cancer (Konkalmatt et al. 2013).

Fluorescent labeled peptide imaging is similar to radiolabeled peptide imaging designation, and is widely used for cancer research and early diagnosis. For instance, bladder cancer is a common disease worldwide with an increasing incidence. The cost of patient from diagnosis to death is almost the highest of all cancers due to varied outcomes, frequent follow-up and scarce diagnostic methods in early stages. Yang et al. successfully isolated and identified a peptide (CSSPIGRHC) with high affinity and specificity targeting to bladder cancer cell BIU-87 by phage display. The peptide synthesized and conjugated with FITC provides a promising diagnostic imaging approach for bladder cancer in humans (Yang et al. 2016). Dysplasia is a pre-malignant status in Barrett's esophagus that is difficult to detect on screening endoscopy because of its flat architecture and patchy distribution. A Cy5.5-labeled 12mer peptide, SRRPASFRTARE specifically binding to Barrett's esophagus was selected, characterized, and reported as a candidate to be developed as a probe for the detection of early esophagus cancer and pre-malignant mucosa (Zhou et al. 2017). By now, fluorescent labeled peptide probes have been successfully used in imaging diagnosis of multiple tumors (Haque et al. 2019; Hou et al. 2018; Jing et al. 2018; Lee et al. 2016; Li et al. 2017; Scodeller et al. 2017; Xing et al. 2018; Zhang et al. 2015).

\section{Nanoparticles-Based Peptides}

The fast development of nanotechnology provides novel approaches to cancer diagnosis by a targeted, efficient and safe way. Nanoparticles can be used as probes in in vivo imaging, biosensing, and immunostaining because of their unique physical and physiochemical properties. First of all, nanoparticles are small enough and can enter tumor microenvironment using an active transport mechanism through endothelial cells (Sindhwani et al. 2020). Secondly, they have relatively large surface areas to accommodate diverse probe molecules, increase the targeting affinity of individual probe, and are ideal for efficient modification with a variety of targeting and imaging moieties. Thirdly, they exhibit high sensitivity. Many nanoparticles show unique magnetic, optical properties and enable multivalent targeting to one or more biomarkers. Lastly, they can also be engineered as suitable platforms for tumor therapy and diagnosis by prolonging half-lives, enhancing stability, and improving targeting efficiency (Baetke et al. 2015; Chen et al. 2013; Lee et al. 2010). The well-investigated nanoparticles include magnetic nanoparticles, quantum dots, gold nanoparticles, polymeric nanoparticles, upconversion nanoparticles, carbon nanoparticles, silicon nanoparticles, and many others.

Selected peptides have been conjugated to nanoparticles and extensively used to cancer imaging. Carbon nanoparticles have shown potential as contrast agents for photoacoustic imaging of tumors because they offer high spatial resolution and allow deep tissue imaging. Gambhir's group fabricated single-walled carbon nanotubes conjugated with cyclic RGD peptides as targeting contrast agents for noninvasive cancer imaging and allowed the visualization of multiple molecular processes in living subjects (de la Zerda et al. 2012). Polymer nanoparticles possess excellent optical properties, high structural flexibility and photostability, and are considered as good near-infrared photoacoustic probes for in vivo real-time imaging of many diseases ( $\mathrm{Li}$ et al. 2018). In a study, an atherosclerotic plaque-homing peptide (CRKRLDRNC, termed AP peptide) conjugated with hydrophobically modified glycol chitosan (HGC) nanoparticles 
showed higher binding affinity to atherosclerotic lesions in a low-density lipoprotein receptor-deficient mouse, results indicated that AP-tagged HGC nanoparticles may be useful for atherosclerotic disease imaging and elucidate pathophysiological changes on atherosclerotic endothelium (Park et al. 2008). Moreover, the nanoprobe of peptide RGDfC conjugated with gold nanoparticles and InP/ZnS quantum dots had excellent tumor targeting dual-mode imaging capabilities, and showed great promise in diagnosis of cancer (Zhang et al. 2018).

Typically, less than $10 \%$ of administered nanoparticles can accumulate in the tumor. By now, researchers have made various improvements to solve this problem. Firstly, we can improve physicochemical properties of nanoparticles to reduce or eliminate serum protein adsorption to enhance the tumor accumulation (Lazarovits et al. 2015). Secondly, restoring functionality of the tumor vasculature maybe a possible treatment strategy to improve drug delivery (Wirthl et al. 2020). Lastly, nanomedicines have been extensively combined with immunotherapy to improve treatment efficacy by modulating the tumor immune microenvironment (Saeed et al. 2019; Shi et al. 2020). Nanoparticles combined with tumor-homing peptides can further enhance the targeting ability of nanoparticles and produce more specific imaging information, which may represent a promising and attractive direction for tumor-targeted diagnosis and therapy.

\section{Peptides for Pharmaceutical Targeting Therapy}

Conventional cancer therapies mainly focus on mass cell killing and often cause severe systemic side effects due to non-specific exposure of anticancer drugs to normal tissues. Pharmaceutical targeting therapy is attracting intensive attentions nowadays, which can effectively and specifically target tumor cells and improve the local chemotherapy drug efficacy ( $\mathrm{Li}$ and Cho 2012). Tumor-homing peptides isolated from phage display libraries can be used as targeting molecules for specific delivery, and it may offer new opportunities for cancer prevention and treatment.

A peptide CSP3 specifically binding to cervical cancer cells was identified, synthesized and conjugated liposomes containing doxorubicin and microRNA101 improved the therapeutic effectiveness of the chemotherapeutic drug by selectively increasing its concentrations in tumors. Therefore, CSP3 peptide may have significant potential in enhancing the clinical efficacy of chemotherapy in cervical cancer (Li et al. 2017; Xiao et al. 2019). Human tumor endothelial cells (TEC) derived from renal carcinomas were injected subcutaneously into severe combined immunodeficiency mice and in vivo biopanning was performed. The identified cyclic peptide BB1, CVGNDNSSC, was capable of specific binding to TEC in vivo and in vitro. Furthermore, conjugation of the peptide to ribosome-inactivating toxin saporin led to a strong apoptotic response in the malignant tissue without impairing other organs such as kidney and liver. The peptide BB1 provides new potential for delivering antitumor agents (Bussolati et al. 2007).

Blood brain barrier (BBB) is formed by tight junctions and plays an effective way to protect the brain from harmful and toxic substances, at the same time, it hampers therapeutical drugs delivery to the central nervous system. To solve the problem of drug delivery across the BBB, the brain specific peptide (TGNYKALHPHNG, Pep TGN) conjugated to the surface of polyethylene glycol-poly (lactic-co-glycolic acid) nanoparticles led to significant higher cellular uptake and in vivo brain accumulation ( $\mathrm{Li}$ et al. 2011). Subsequently, researchers found intravenous administration of the TGN modified nanoparticles could obviously improve the learning and memory deficits in the mice model of Alzheimer's disease. Pep TGN can facilitate nanoparticles to traverse the BBB from the system circulation and can be applied to drug delivery system homing to the brain for therapy ( $\mathrm{Li}$ et al. 2013b). Li et al. discovered Syp-1 peptide GNKRTRG bound specifically to tumor and endothelial cells of tumor lymphatics could efficiently mediate tumor uptake of liposomal doxorubicin and show enhanced antitumor effects. Syp-1 is a stable and effective tumor targeting ligand and may strongly support the validity of peptide-mediated drug targeting therapy (Li et al. 2013a). Kelly et al. designed PTP liposomal AZ7379 (a PARP inhibitor) delivery apparently decreased tumor growth and volume of ovarian cancer, which provides new opportunity to extend the treat efficiency of diseases (Dasa et al. 2018).

Several peptide drugs isolated from phage display are also used widely in the clinic or are in clinical trials. For example, Fuzeon (enfuvirtide), the first peptide inhibitor on the market for HIV treatment (Matthews et al. 2004), was discovered, established and launched in March 2003 through a series of studies by Trimeris and Roche. Goserelin, a peptide suppressing production of luteinizing hormone releasing hormone, had been approved by the Food and Drug Administration for the treatment of the breast and prostate cancer, and some benign gynaecological disorders (D'Amico 2014). DX-890, an inhibitor of human neutrophil elastase, with the potential treatment of pulmonary diseases such as cystic fibrosis and chronic obstructive pulmonary disease, is currently in phase II clinical trials (Wark 2002). Romiplostim, a ligand for thrombopoietin receptor, is an effective treatment in children with immune thrombocytopenia and is now in phase III (Tarantino et al. 2016).

Peptides possess advantages for the development of antitumor drugs, such as high affinity, good solubility properties, low toxicity and immunogenicity, but they also face several practical hurdles, including low oral bioavailability, rapid degradation by proteolytic enzymes, short half-life and poor solubility. Notably, absorption, distribution and metabolism 
processes play important roles in defining the disposition of a drug candidate. To develop a peptide as an excellent therapeutic agent, many strategies are employed to overcome the limitations. They include (I) optimizing chemical structures (cyclization, bioisosteric replacement of peptide bonds, changing the stereochemistry of an amino acid) to increase stability, bioavailability and sensitivity (Belhadj et al. 2017; Ying et al. 2016), (II) producing prodrugs and analogs of biologicals to protect the peptide from degradation (Morishita and Peppas 2006), (III) using transport-carrier molecules to introduce novel functionality to improve absorption of the peptide (Khafagy el and Morishita 2012), (IV) D-amino acids substitution to enhance therapeutic effects (Tada et al. 2011), and (V) adding polyethylene glycol, human serum albumin, or Fc fragment of human $\operatorname{IgG}$ to increase circulation time of the peptide ( $\mathrm{Li}$ et al. 2019b).

\section{Conclusion}

Phage displayed peptide library has been proved an effective and powerful method that allows vast sequence screening and tumor binding peptides identifying. A complete workflow of phage display screen is illustrated in Fig. 2. In recent years, peptides have been labeled with radionuclides, fluorophores or conjugated with nanoparticles for the imaging of a range of tumors to improve early detection or response to therapy. Some can also be modified for pharmaceutical targeting therapy to facilitate the clinical efficacy of chemotherapy in the treatment and offer new opportunities for cancer prevention. Peptides own many advantages in clinical applications, however, identification of a peptide receptor is more difficult than discovery of a tumor-binding peptide. Some homing peptides are found together with their receptors through yeast two-hybrid, co-immunoprecipitation or affinity chromatography combined with protein mass spectrometry. Intrinsic characteristics of membrane proteins may be responsible for the low identification. Furthermore, specificity of the peptides may emerge not from total protein expression but from a rearrangement of receptors on the cell surface. This information will be lost upon the destruction of structural conformation of membrane proteins for affinity purification. Additionally, it is possible that the receptors may not proteins, but the motifs of phospholipids or carbohydrates located on the cell surface. Besides, the identification is time-consuming, labor-intensive, complex and costly. Hence, if the screening targets are known, further researches can be conducted to validate peptide properties such as effects on cell cycle, cell proliferation, cell migration and apoptosis (Kim et al. 2014). In addition, investigators have already developed an efficient method for screening a large number of peptides in parallel to identify peptide receptors or targeting sites, which was termed as "reverse biopanning" (Ferraro et al. 2013) .

Another concern is that the use of peptide in animals is gaining widespread stability and acceptability, however, the use in humans still faces barriers including immunogenicity and clearance problems. Therefore, further pre-clinical trials
Fig. 2 A complete workflow of phage display screen

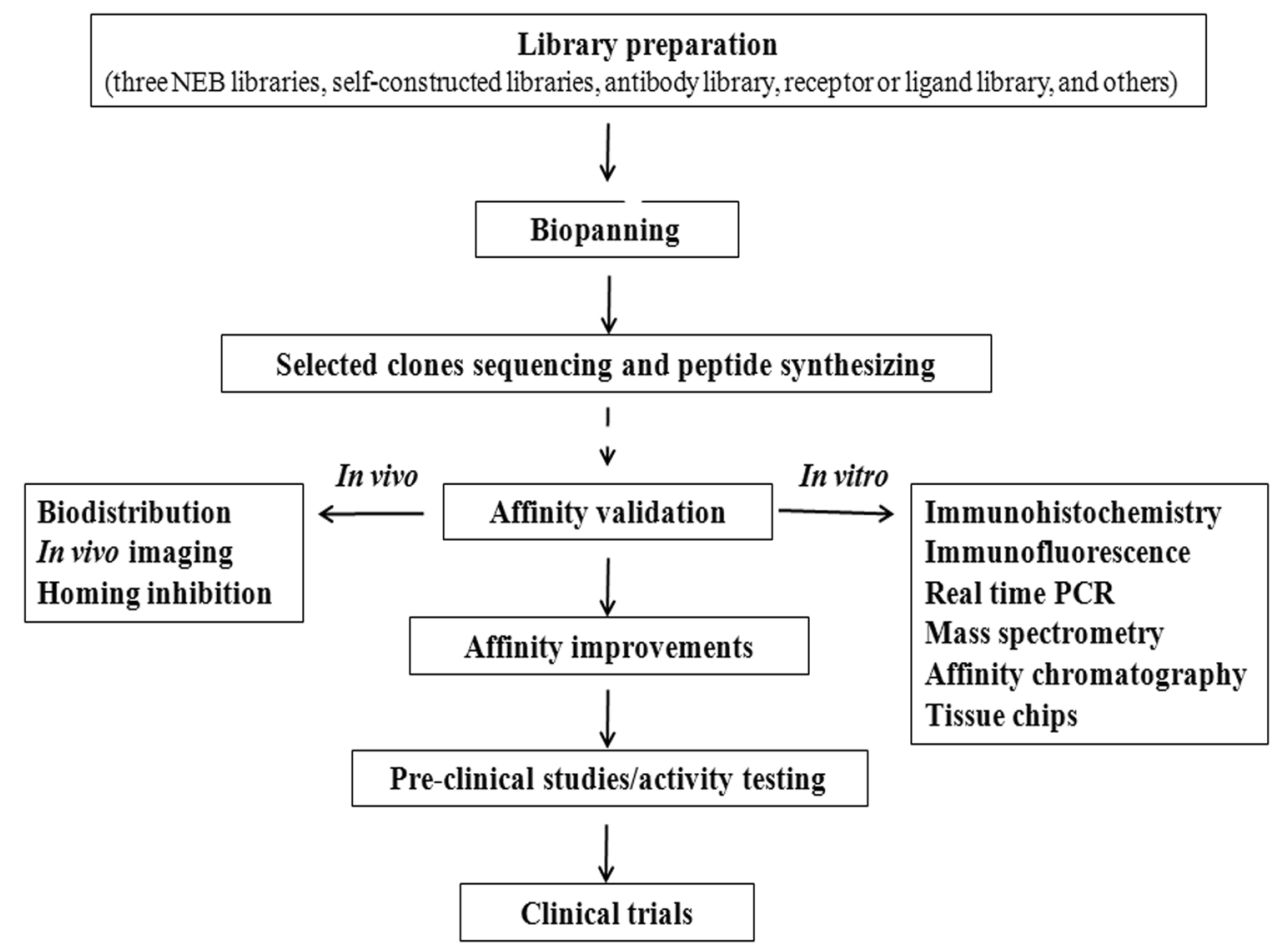


and improvements should be hold to overcome these problems. Currently, the combination of peptide and nanopraticles may provide an attractive approach because of superior properties of nanoparticles such as better tumor penetrating ability, high sensitivity, super capability to carry therapeutic agents, and high quality of imaging information.

Taken together, the advent of peptide and nanomaterial technologies provides the new approaches to design and analyze biologically active molecules rapidly. These molecules take important potential to be used for tumor imaging diagnosis and targeting therapy. The current studies combining targeting peptide and nanomaterial are not tried enough to induce practically useful products for tumor early detection and targeting therapy, so a lot of effort is still in need for further research.

Acknowledgements This work was supported by the First Affiliated Hospital of Air Force Medical University (No. XJZT18MJ54 and No. XJZT18MJ53) and University Joint Project of Shaanxi (2020GXLH-Y-009).

\section{Compliance with Ethical Standards}

Conflict of interest The authors declare no conflict of interest.

Research Involving Human and/or Animal Rights The article does not contain any studies with human participants or with animals by any of the authors.

\section{References}

Acharya B, Meka RR, Venkatesha SH, Lees JR, Teesalu T, Moudgil KD (2020) A novel CNS-homing peptide for targeting neuroinflammatory lesions in experimental autoimmune encephalomyelitis. Mol Cell Probes. https://doi.org/10.1016/j.mcp.2020.101530

Armbruster DA (1993) Prostate-specific antigen: biochemistry, analytical methods, and clinical application. Clin Chem 39:181-195

Baetke SC, Lammers T, Kiessling F (2015) Applications of nanoparticles for diagnosis and therapy of cancer. Br J Radiol 88:20150207. https://doi.org/10.1259/bjr.20150207

Belhadj Z et al (2017) Design of Y-shaped targeting material for liposome-based multifunctional glioblastoma-targeted drug delivery. J Control Release 255:132-141. https://doi.org/10.1016/j.jconr el.2017.04.006

Bray F, Ferlay J, Soerjomataram I, Siegel RL, Torre LA, Jemal A (2018) Global cancer statistics 2018: GLOBOCAN estimates of incidence and mortality worldwide for 36 cancers in 185 countries. CA Cancer J Clin 68:394-424. https://doi.org/10.3322/ caac. 21492

Bussolati B, Grange C, Tei L, Deregibus MC, Ercolani M, Aime S, Camussi G (2007) Targeting of human renal tumor-derived endothelial cells with peptides obtained by phage display. J Mol Med (Berl) 85:897-906. https://doi.org/10.1007/s0010 9-007-0184-3

Capula M, Mantini G, Funel N, Giovannetti E (2019) New avenues in pancreatic cancer: exploiting microRNAs as predictive biomarkers and new approaches to target aberrant metabolism. Expert Rev Clin Pharmacol 12:1081-1090. https://doi.org/10.1080/17512 433.2019.1693256
Carneiro AP et al (2014) A putative OTU domain-containing protein 1 deubiquitinating enzyme is differentially expressed in thyroid cancer and identifies less-aggressive tumours. Br J Cancer 111:551-558. https://doi.org/10.1038/bjc.2014.331

Chen H, Zhen Z, Todd T, Chu PK, Xie J (2013) Nanoparticles for improving cancer diagnosis. Mater Sci Eng R 74:35-69. https ://doi.org/10.1016/j.mser.2013.03.001

Costante G, Meringolo D (2020) Calcitonin as a biomarker of C cell disease: recent achievements and current challenges. Endocrine 67:273-280. https://doi.org/10.1007/s12020-019-02183-6

D’Amico AV (2014) US Food and Drug Administration approval of drugs for the treatment of prostate cancer: a new era has begun. J Clin Oncol 32:362-364. https://doi.org/10.1200/ JCO.2013.53.9528

Dasa SSK et al (2018) Plectin-targeted liposomes enhance the therapeutic efficacy of a PARP inhibitor in the treatment of ovarian cancer. Theranostics 8:2782-2798. https://doi.org/10.7150/ thno. 23050

de la Zerda A et al (2012) Family of enhanced photoacoustic imaging agents for high-sensitivity and multiplexing studies in living mice. ACS Nano 6:4694-4701. https://doi.org/10.1021/nn204 $352 \mathrm{r}$

Deutscher SL (2010) Phage display in molecular imaging and diagnosis of cancer. Chem Rev 110:3196-3211. https://doi.org/10.1021/ cr900317f

Feng F et al (2017) Diagnostic and prognostic value of CEA, CA19-9, AFP and CA125 for early gastric cancer. BMC Cancer 17:737. https://doi.org/10.1186/s12885-017-3738-y

Ferraro DJ et al (2013) High-throughput identification of putative receptors for cancer-binding peptides using biopanning and microarray analysis. Integr Biol (Camb) 5:342-350. https://doi. org/10.1039/c2ib20187a

Ferreira D et al (2019) Rational identification of a colorectal cancer targeting peptide through phage display. Sci Rep 9:3958. https:// doi.org/10.1038/s41598-019-40562-1

Fouladi M et al (2019) Selection of a fully human single domain antibody specific to Helicobacter pylori urease. Appl Microbiol Biotechnol 103:3407-3420. https://doi.org/10.1007/s00253-01909674-6

Funamizu N, Lacy CR, Kamada M, Yanaga K, Manome Y (2019) MicroRNA-200b and -301 are associated with gemcitabine response as biomarkers in pancreatic carcinoma cells. Int J Oncol 54:991-1000. https://doi.org/10.3892/ijo.2019.4676

Gallo E et al (2020) In situ antibody phage display yields optimal inhibitors of integrin alpha11/beta1. MAbs 12:1717265. https:// doi.org/10.1080/19420862.2020.1717265

Ghosh A, Woolum K, Kothandaraman S, Tweedle MF, Kumar K (2019) Stability evaluation and stabilization of a gastrin-releasing peptide receptor (GRPR) targeting imaging pharmaceutical. Molecules. https://doi.org/10.3390/molecules 24162878

Haque ME et al (2019) A phage display-identified peptide selectively binds to kidney injury molecule-1 (KIM-1) and detects KIM1-overexpressing tumors in vivo. Cancer Res Treat 51:861-875. https://doi.org/10.4143/crt.2018.214

Hintz HM, Cowan AE, Shapovalova M, LeBeau AM (2019) Development of a cross-reactive monoclonal antibody for detecting the tumor stroma. Bioconjug Chem 30:1466-1476. https://doi. org/10.1021/acs.bioconjchem.9b00206

Hou L et al (2018) Identification of a specific peptide binding to colon cancer cells from a phage-displayed peptide library. Br J Cancer 118:79-87. https://doi.org/10.1038/bjc.2017.366

Jing R et al (2018) Fluorescent peptide highlights micronodules in murine hepatocellular carcinoma models and humans in vitro. Hepatology 68:1391-1411. https://doi.org/10.1002/hep.29829

Kehoe JW et al (2006) Using phage display to select antibodies recognizing post-translational modifications independently of 
sequence context. Mol Cell Proteomics 5:2350-2363. https://doi. org/10.1074/mcp.M600314-MCP200

Kelly KA et al (2008a) Targeted nanoparticles for imaging incipient pancreatic ductal adenocarcinoma. PLoS Med 5:e85. https://doi. org/10.1371/journal.pmed.0050085

Kelly KA, Setlur SR, Ross R, Anbazhagan R, Waterman P, Rubin MA, Weissleder R (2008b) Detection of early prostate cancer using a hepsin-targeted imaging agent. Cancer Res 68:2286-2291. https ://doi.org/10.1158/0008-5472.CAN-07-1349

Khafagy el S, Morishita M (2012) Oral biodrug delivery using cellpenetrating peptide. Adv Drug Deliv Rev 64:531-539. https://doi. org/10.1016/j.addr.2011.12.014

Khemthongcharoen N, Jolivot R, Rattanavarin S, Piyawattanametha W (2014) Advances in imaging probes and optical microendoscopic imaging techniques for early in vivo cancer assessment. Adv Drug Deliv Rev 74:53-74. https://doi.org/10.1016/j.addr.2013.09.012

Kim D et al (2014) A specific STAT3-binding peptide exerts antiproliferative effects and antitumor activity by inhibiting STAT3 phosphorylation and signaling. Cancer Res 74:2144-2151. https://doi. org/10.1158/0008-5472.CAN-13-2187

Konkalmatt PR, Deng D, Thomas S, Wu MT, Logsdon CD, French BA, Kelly KA (2013) Plectin-1 targeted AAV vector for the molecular imaging of pancreatic. Cancer Front Oncol 3:84. https://doi. org/10.3389/fonc.2013.00084

Kossatz S, Behe M, Mansi R, Saur D, Czerney P, Kaiser WA, Hilger I (2013) Multifactorial diagnostic NIR imaging of CCK2R expressing tumors. Biomaterials 34:5172-5180. https://doi.org/10.1016/j. biomaterials.2013.03.073

Kugler J, Zantow J, Meyer T, Hust M (2013) Oligopeptide m13 phage display in pathogen research. Viruses 5:2531-2545. https://doi. org/10.3390/v5102531

Lang Q, Wang F, Yin L, Liu M, Petrenko VA, Liu A (2014) Specific probe selection from landscape phage display library and its application in enzyme-linked immunosorbent assay of free prostate-specific antigen. Anal Chem 86:2767-2774. https://doi. org/10.1021/ac404189k

Larimer BM, Thomas WD, Smith GP, Deutscher SL (2014) Affinity maturation of an ERBB2-targeted SPECT imaging peptide by in vivo phage display. Mol Imaging Biol 16:449-458. https://doi. org/10.1007/s11307-014-0724-5

Larimer BM, Phelan N, Wehrenberg-Klee E, Mahmood U (2018) Phage display selection, in vitro characterization, and correlative PET imaging of a novel HER3 peptide. Mol Imaging Biol 20:300-308. https://doi.org/10.1007/s11307-017-1106-6

Lazarovits J, Chen YY, Sykes EA, Chan WC (2015) Nanoparticleblood interactions: the implications on solid tumour targeting. Chem Commun (Camb) 51:2756-2767. https://doi.org/10.1039/ c4cc07644c

Lee S, Xie J, Chen X (2010) Peptide-based probes for targeted molecular imaging. Biochemistry 49:1364-1376. https://doi.org/10.1021/ bi901135x

Lee KJ, Lee JH, Chung HK, Ju EJ, Song SY, Jeong SY, Choi EK (2016) Application of peptide displaying phage as a novel diagnostic probe for human lung adenocarcinoma. Amino Acids 48:1079_ 1086. https://doi.org/10.1007/s00726-015-2153-4

Li ZJ, Cho CH (2010) Development of peptides as potential drugs for cancer therapy. Curr Pharm Des 16:1180-1189. https://doi. org/10.2174/138161210790945913

Li ZJ, Cho CH (2012) Peptides as targeting probes against tumor vasculature for diagnosis and drug delivery. J Transl Med 10(Suppl 1):S1. https://doi.org/10.1186/1479-5876-10-S1-S1

Li J, Rao J, Pu K (2018) Recent progress on semiconducting polymer nanoparticles for molecular imaging and cancer phototherapy. Biomaterials 155:217-235. https://doi.org/10.1016/j.biomateria 1s.2017.11.025
Li J et al (2011) Targeting the brain with PEG-PLGA nanoparticles modified with phage-displayed peptides. Biomaterials 32:49434950. https://doi.org/10.1016/j.biomaterials.2011.03.031

Li J et al (2013a) Brain delivery of NAP with PEG-PLGA nanoparticles modified with phage display peptides. Pharm Res 30:18131823. https://doi.org/10.1007/s11095-013-1025-4

Li C, Wang Y, Zhang X, Deng L, Zhang Y, Chen Z (2013b) Tumortargeted liposomal drug delivery mediated by a diseleno bondstabilized cyclic peptide. Int J Nanomed 8:1051-1062. https:// doi.org/10.2147/IJN.S40498

Li C et al (2017) Screening and identification of a specific peptide binding to cervical cancer cells from a phage-displayed peptide library. Biotechnol Lett 39:1463-1469. https://doi.org/10.1007/ s10529-017-2381-7

Li M et al (2019a) Enhancing the efficacy of melanocortin 1 receptortargeted radiotherapy by pharmacologically upregulating the receptor in metastatic melanoma. Mol Pharm 16:3904-3915. https ://doi.org/10.1021/acs.molpharmaceut.9b00512

Li Y, Wang X, Chen Y, Yang Z, Jiang ZX (2019b) Monodisperse polyethylene glycol "brushes" with enhanced lipophilicity, and thermo and plasma stability. Chem Commun (Camb) 55:1895-1898. https ://doi.org/10.1039/c8cc09151j

Licha K, Olbrich C (2005) Optical imaging in drug discovery and diagnostic applications. Adv Drug Deliv Rev 57:1087-1108. https:// doi.org/10.1016/j.addr.2005.01.021

Lim CC, Woo PCY, Lim TS (2019) Development of a phage display panning strategy utilizing crude antigens: isolation of MERSCoV nucleoprotein human antibodies. Sci Rep 9:6088. https:// doi.org/10.1038/s41598-019-42628-6

Liu F et al (2018) Design, synthesis, and biological evaluation of (68) Ga-DOTA-PA1 for lung cancer: a novel PET tracer for multiple somatostatin receptor imaging. Mol Pharm 15:619-628. https:// doi.org/10.1021/acs.molpharmaceut.7b00963

Lu RM et al (2013) Targeted drug delivery systems mediated by a novel Peptide in breast cancer therapy and imaging. PLoS ONE 8:e66128. https://doi.org/10.1371/journal.pone.0066128

Luna Coronell JA, Syed P, Sergelen K, Gyurjan I, Weinhausel A (2012) The current status of cancer biomarker research using tumourassociated antigens for minimal invasive and early cancer diagnostics. J Proteomics. https://doi.org/10.1016/j.jprot.2012.07.022

Luo G et al (2018) New observations on the utility of CA19-9 as a biomarker in Lewis negative patients with pancreatic cancer. Pancreatology 18:971-976. https://doi.org/10.1016/j.pan.2018.08.003

Martins IM, Reis RL, Azevedo HS (2016) Phage display technology in biomaterials engineering: progress and opportunities for applications in regenerative medicine. ACS Chem Biol 11:2962-2980. https://doi.org/10.1021/acschembio.5b00717

Matthews T, Salgo M, Greenberg M, Chung J, DeMasi R, Bolognesi D (2004) Enfuvirtide: the first therapy to inhibit the entry of HIV-1 into host CD4 lymphocytes. Nat Rev Drug Discov 3:215-225. https://doi.org/10.1038/nrd1331

Mezzanotte L, van 't Root M, Karatas H, Goun EA, Lowik C (2017) In vivo molecular bioluminescence imaging: new tools and applications. Trends Biotechnol 35:640-652. https://doi.org/10.1016/j. tibtech.2017.03.012

Miao P, Sheng S, Sun X, Liu J, Huang G (2013) Lactate dehydrogenase A in cancer: a promising target for diagnosis and therapy. IUBMB Life 65:904-910. https://doi.org/10.1002/iub.1216

Morishita M, Peppas NA (2006) Is the oral route possible for peptide and protein drug delivery? Drug Discov Today 11:905-910. https ://doi.org/10.1016/j.drudis.2006.08.005

Newman MR, Benoit DSW (2018) In vivo translation of peptide-targeted drug delivery systems discovered by phage display. Bioconjug Chem 29:2161-2169. https://doi.org/10.1021/acs.bioco njchem. 8 b00285 
Park K, Hong HY, Moon HJ, Lee BH, Kim IS, Kwon IC, Rhee K (2008) A new atherosclerotic lesion probe based on hydrophobically modified chitosan nanoparticles functionalized by the atherosclerotic plaque targeted peptides. J Control Release 128:217223. https://doi.org/10.1016/j.jconrel.2008.03.019

Rahbarnia L, Farajnia S, Babaei H, Majidi J, Veisi K, Khosroshahi SA, Tanomand A (2017) Development of a novel human scFv against EGFR L2 domain by phage display technology. Curr Pharm Des 23:2009-2014. https://doi.org/10.2174/13816128226661609281 12208

Rangel R et al (2012) Combinatorial targeting and discovery of ligandreceptors in organelles of mammalian cells. Nat Commun 3:788. https://doi.org/10.1038/ncomms1773

Riccetti L, De Pascali F, Gilioli L, Santi D, Brigante G, Simoni M, Casarini L (2017) Genetics of gonadotropins and their receptors as markers of ovarian reserve and response in controlled ovarian stimulation. Best Pract Res Clin Obstet Gynaecol 44:15-25. https ://doi.org/10.1016/j.bpobgyn.2017.04.002

Saeed M, Gao J, Shi Y, Lammers T, Yu H (2019) Engineering nanoparticles to reprogram the tumor immune microenvironment for improved. Cancer Immunother Theranostics 9:7981-8000. https ://doi.org/10.7150/thno.37568

Scodeller P et al (2017) Precision Targeting of tumor macrophages with a CD206 binding peptide. Sci Rep 7:14655. https://doi. org/10.1038/s41598-017-14709-X

Shi Y, van der Meel R, Chen X, Lammers T (2020) The EPR effect and beyond: strategies to improve tumor targeting and cancer nanomedicine treatment efficacy. Theranostics 10:7921-7924. https:// doi.org/10.7150/thno. 49577

Sindhwani $S$ et al (2020) The entry of nanoparticles into solid tumours. Nat Mater 19:566-575. https://doi.org/10.1038/s4156 3-019-0566-2

Smith GP (1985) Filamentous fusion phage: novel expression vectors that display cloned antigens on the virion surface. Science 228:1315-1317. https://doi.org/10.1126/science.4001944

Stahle $\mathrm{M}$ et al (2018) Glucagon-like peptide-1 receptor expression after myocardial infarction: imaging study using (68)Ga-NODAGAexendin-4 positron emission tomography. J Nucl Cardiol. https:// doi.org/10.1007/s12350-018-01547-1

Sturm MB et al (2013) Targeted imaging of esophageal neoplasia with a fluorescently labeled peptide: first-in-human results. Sci Transl Med 5:184ra161. https://doi.org/10.1126/scitranslmed.3004733

Tada N, Horibe T, Haramoto M, Ohara K, Kohno M, Kawakami K (2011) A single replacement of histidine to arginine in EGFRlytic hybrid peptide demonstrates the improved anticancer activity . Biochem Biophys Res Commun 407:383-388. https://doi. org/10.1016/j.bbrc.2011.03.030

Tarantino MD et al (2016) Romiplostim in children with immune thrombocytopenia: a phase 3 , randomised, double-blind, placebocontrolled study. Lancet 388:45-54. https://doi.org/10.1016/ S0140-6736(16)00279-8

Thanongsaksrikul $\mathrm{J}$ et al (2018) Identification and production of mouse scFv to specific epitope of enterovirus-71 virion protein-2 (VP2). Arch Virol 163:1141-1152. https://doi.org/10.1007/s0070 5-018-3731-z

Ulaner GA et al (2018) First-in-human human epidermal growth factor receptor 2-targeted imaging using (89)Zr-pertuzumab PET/ CT: dosimetry and clinical application in patients with breast cancer. J Nucl Med 59:900-906. https://doi.org/10.2967/jnume d.117.202010
Velappan N et al (2019) Selection and characterization of FcepsilonRI phospho-ITAM specific antibodies. MAbs 11:1206-1218. https:// doi.org/10.1080/19420862.2019.1632113

Wada A, Terashima T, Kageyama S, Yoshida T, Narita M, Kawauchi A, Kojima H (2019) Efficient prostate cancer therapy with tissue-specific homing peptides identified by advanced phage display technology. Mol Ther Oncolytics 12:138-146. https://doi. org/10.1016/j.omto.2019.01.001

Wark PA (2002) DX-890 (Dyax). IDrugs 5:586-589

Wirthl B, Kremheller J, Schrefler BA, Wall WA (2020) Extension of a multiphase tumour growth model to study nanoparticle delivery to solid tumours. PLoS ONE 15:e0228443. https://doi.org/10.1371/ journal.pone. 0228443

Xiao L et al (2019) Development of a novel drug targeting delivery system for cervical cancer therapy. Nanotechnology 30:075604. https://doi.org/10.1088/1361-6528/aaf3f8

Xing L et al (2018) Identification of a peptide for folate receptor alpha by phage display and its tumor targeting activity in ovary cancer xenograft. Sci Rep 8:8426. https://doi.org/10.1038/s41598-01826683-z

Yang X et al (2016) A new non-muscle-invasive bladder tumor-homing peptide identified by phage display in vivo. Oncol Rep 36:79-89. https://doi.org/10.3892/or.2016.4829

Yeh CY, Hsiao JK, Wang YP, Lan CH, Wu HC (2016) Peptide-conjugated nanoparticles for targeted imaging and therapy of prostate cancer. Biomaterials 99:1-15. https://doi.org/10.1016/j.biomateria 1s.2016.05.015

Yin X et al (2017) Evaluation of neurotensin receptor 1 as a potential imaging target in pancreatic ductal adenocarcinoma. Amino Acids 49:1325-1335. https://doi.org/10.1007/s00726-017-2430-5

Ying $\mathrm{M}$ et al (2016) A stabilized peptide ligand for multifunctional glioma targeted drug delivery. J Control Release 243:86-98. https ://doi.org/10.1016/j.jconrel.2016.09.035

Zhang D et al (2015) A CD44 specific peptide developed by phage display for targeting gastric cancer. Biotechnol Lett 37:2311-2320. https://doi.org/10.1007/s10529-015-1896-z

Zhang L et al (2018) In vivo tumor active cancer targeting and CTfluorescence dual-modal imaging with nanoprobe based on gold nanorods and InP/ZnS quantum dots. J Mater Chem B 6:25742583. https://doi.org/10.1039/c7tb02643a

Zhang D, Jia H, Li W, Hou Y, Lu S, He S (2016) Screening and identification of a phage display derived peptide that specifically binds to the CD44 protein region encoded by variable exons. J Biomol Screen 21:44-53. https://doi.org/10.1177/1087057115608604

Zhao Y et al (2018) Discovery and characterization of a high-affinity small peptide ligand, H1, targeting FGFR2IIIc for skin wound healing. Cell Physiol Biochem 49:1033-1048. https://doi. org/10.1159/000493287

Zhou J et al (2017) Identification and validation of FGFR2 peptide for detection of early Barrett's neoplasia. Oncotarget 8:87095-87106. https://doi.org/10.18632/oncotarget.19764

Publisher's Note Springer Nature remains neutral with regard to jurisdictional claims in published maps and institutional affiliations. 